\title{
Are aggressive deliveries of very preterm babies justified?
}

\author{
Jijisha Ali ${ }^{1}$, Roopa Padavagodu Shivananda ${ }^{1} *$, Rajeshwari G Bhat ${ }^{1}$, Aiswarya Sankar ${ }^{2}$, \\ Pratap Kumar ${ }^{1}$, Lavanya Rai ${ }^{1}$
}

\author{
${ }^{1}$ Department of Obstetrics and Gynaecology, ${ }^{2}$ Deparment of Paediatrics, Kasturba Medical College, Manipal \\ University, Manipal, Karnataka, India
}

Received: 07 March 2016

Accepted: 09 April 2016

\section{*Correspondence: \\ Dr. Roopa Padavagodu Shivananda, \\ E-mail: roopasarun@gmail.com}

Copyright: ( ) the author(s), publisher and licensee Medip Academy. This is an open-access article distributed under the terms of the Creative Commons Attribution Non-Commercial License, which permits unrestricted non-commercial use, distribution, and reproduction in any medium, provided the original work is properly cited.

\section{ABSTRACT}

Background: Every year there are 15 million babies who are born too soon. The objective of this study was to analyze the neonatal morbidity and mortality of preterm neonates at birth.

Methods: This was a prospective study conducted in the department of obstetrics and gynecology and neonatology. We included all preterm deliveries from 26 weeks to 36 weeks 6 days period of gestation in one year. Neonatal morbidities and mortalities at birth were noted.

Results: The rate of preterm birth was $8.49 \%$. Spontaneous preterm labor accounted for $52 \%$ of the causes of preterm. Hyperbilirubinemia was the commonest neonatal morbidity affecting $53.2 \%$ of the neonates. Respiratory distress syndrome (RDS) and sepsis was highest in neonates of 26 weeks to 28 weeks gestation. This group saw a mortality of $90 \%$.

Conclusions: Prematurity is associated with high mortality and long-term morbidity. Low APGARS might be good predictors of neonatal/ infant mortality. In the extremely preterm neonate, it may prove worthy to weigh the risks and benefits and thereafter counsel the mother and concerned relatives accordingly to help with decision making.

Keywords: "Very" preterm babies, Aggressive deliveries, Neonatal morbidity and mortality

\section{INTRODUCTION}

Preterm labour is a bane for an obstetrician. Its prevention and management still remains a challenge. Every year there are 15 million babies who are born too soon. The global rate of preterm birth has been in the range of $5 \%$ to $18 \% .{ }^{1}$ India ranks first in terms of highest number of preterm births $(35,19,100) .^{2}$ The rate of premature births in India is $21 \% .^{3}$ The prevalence of preterm birth has been the same or is in fact, rising over a period of decades. Complications of preterm birth claim 1 million children every year. ${ }^{1}$ Those children, who survive, may have long term morbidities in which cerebral palsy, neurodevelopment delays and learning disabilities are of prime importance. Preterm births account for $75 \%$ of perinatal mortality and morbidity. Globally, prematurity is the leading cause of new-born deaths. The millennium development goal (MDG) aims to reduce child mortality by two third by $2015 .^{4}$ In order to achieve this, India has to decrease the rising trend of preterm births as, $40 \%$ of under-five deaths are in newborns, with prematurity being the leading cause of deaths in the new-borns. ${ }^{5}$ The highly evolved neonatal intensive care units (NICU), with the use of antenatal corticosteroids have lowered the gestational age of salvagibility of preterm neonates. But this decreasing trend has overburdened us with the survival of these extreme preterm neonates with a questionable neurological outcome later on in life.

In India, the awareness of preterm births is poor. Though it has been recognized as a public health issue by the Indian government, the awareness in the general population is poor. This might be due to the low literacy 
levels. Most of the studies on neonatal morbidities and mortalities have been published by paediatricians. But a sound knowledge of these complications by an obstetrician might improve our decision making. Hence the study has been conducted with the aim to analyse premature babies with respect to morbidity and mortality at birth. The objective of this study was to analyze the neonatal morbidity and mortality of preterm neonates at birth.

\section{METHODS}

This was a prospective study conducted in the department of obstetrics and gynecology and neonatology, Kasturba Medical College, Manipal, India. We included all preterm deliveries between 26 weeks to 36 weeks 6 days period of gestation from May 2012 to April 2013. The term "very" preterm were applied to neonates between 26 to 28 weeks.

Babies with congenital anomalies were excluded from the study.
The weight of the baby at birth, neonatal morbidities in terms of low APGAR score at $5 \mathrm{~min}(<4)$, respiratory distress, sepsis, intra-ventricular hemorrhage, hypoglycemia, hyperbilirubinemia and seizures were noted. We assessed gestational age from 26 weeks onwards to 36 weeks 6 days. We divided them into 5 groups. Group 1: 26 weeks to 28 weeks, group 2: 28 weeks 1 day to 30 weeks, group 3: 30 weeks 1 day to 32 weeks, group 4: 32 weeks 1 day to 34 weeks and the last group, group 5: 34 weeks one day to 36+ weeks 6 days. The neonatal mortalities in each group were also seen.

This study was approved by the institutional ethical committee. Informed consent was taken from the parent.

\section{RESULTS}

There were a total of 3659 deliveries during this period. The preterm deliveries were 311 . The rate of preterm birth was $8.49 \%$. There were a total of 334 preterm babies (21 twins and 1 triplet) whose neonatal morbidities were assessed at birth. Neonatal mortalities were also observed.

Table 1: Neonatal characteristics with respect to gestational age.

\begin{tabular}{|llllll|}
\hline Neonatal characteristics & $\begin{array}{l}26-28 \text { weeks } \\
n=10\end{array}$ & $\begin{array}{l}28-30 \text { weeks } \\
n=24\end{array}$ & $\begin{array}{l}30-32 \text { weeks } \\
n=45\end{array}$ & $\begin{array}{l}32-34 \text { weeks } \\
n=79\end{array}$ & $\begin{array}{l}34-36+\text { weeks } \\
n=176\end{array}$ \\
\hline Average birth weight $(\mathrm{gm})$ & 821.5 & 1140.2 & 1344.7 & 1681.3 & 2183.3 \\
\hline Female gender $(\%)$ & $5(50)$ & $11(45.8)$ & $16(35.5)$ & $35(44.3)$ & $88(50)$ \\
\hline Steroids received $(\%)$ & $10(100)$ & $22(91.7)$ & $40(88.9)$ & $72(91.1)$ & $136(77.3)$ \\
\hline Surfactant received (\%) & $6(60)$ & $17(70.8)$ & $10(22.2)$ & $06(7.5)$ & $01(0.5)$ \\
\hline Route of delivery (\%) (Caesarean) & $6(60)$ & $20(83.3)$ & $37(82.2)$ & $72(91.1)$ & $158(89.7)$ \\
\hline
\end{tabular}

Table 2: Neonatal morbidities with respect to gestational age.

\begin{tabular}{|c|c|c|c|c|c|c|}
\hline Neonatal morbidities & $\begin{array}{l}\text { 26-28 } \\
\text { Weeks n=10 }\end{array}$ & $\begin{array}{l}28-30 \\
\text { weeks } n=24\end{array}$ & $\begin{array}{l}30-32 \\
\text { weeks } n=45\end{array}$ & $\begin{array}{l}32-34 \\
\text { weeks } n=79\end{array}$ & $\begin{array}{l}34-36+ \\
\text { weeks } n=176\end{array}$ & $\begin{array}{l}\text { Total } \\
334(\%)\end{array}$ \\
\hline Apgars $<4(\%)$ & $7(70)$ & $3(12.5)$ & $6(13.3)$ & $5(6.3)$ & $7(6.4)$ & $28(8.3)$ \\
\hline RDS (\%) & $10(100)$ & $20(83.3)$ & $33(73.3)$ & $40(51)$ & $22(21.3)$ & $125(37.4)$ \\
\hline Hypoglycemia (\%) & 0 & $1(4.1)$ & $7(15.6)$ & $8(10.1)$ & $7(6.8)$ & $23(6.8)$ \\
\hline Sepsis (\%) & $7(70)$ & $10(42)$ & $10(22.2)$ & $11(14)$ & $5(4.9)$ & $43(12.8)$ \\
\hline $\begin{array}{l}\text { Intraventricular } \\
\text { Haemorrhage }(\%)\end{array}$ & $1(10)$ & $2(8.3)$ & $1(2.2)$ & 0 & $1(1)$ & $5(1.4)$ \\
\hline Hyperbilirubinemia (\%) & $6(60)$ & $15(62.5)$ & $27(60)$ & $53(67.1)$ & $77(74.8)$ & $178(53.2)$ \\
\hline Seizures (\%) & 0 & $1(4.1)$ & $1(2.2)$ & $1(1.2)$ & $2(1.9)$ & $5(1.4)$ \\
\hline $\begin{array}{l}\text { Duration of hospital stay } \\
(>10 \text { days })(\%)\end{array}$ & $6(60)$ & $22(91.6)$ & $38(84)$ & $50(63.2)$ & 33 (18.7) & $149(44)$ \\
\hline
\end{tabular}

Spontaneous preterm labour accounted for $52 \%$ of the causes of preterm. In the rest $48 \%$ pregnancy was terminated. Among them preeclampsia and eclampsia contributed for $29 \%$ of the medically indicated terminations. Group 2 was the only group, in which eclampsia and preeclampsia contributed highest to termination of pregnancy, in the rest, spontaneous preterm took the share.

(Table 1) shows the characteristics of the neonates. More than $75 \%$ of neonates received steroids in each group. The requirement of additional surfactants was high (60- 
$70 \%$ ) in the first two groups and fell drastically from group 3 onwards. The rate of cesarean delivery was high in each of the preterm groups $(>50 \%)$.

(Table 2) shows the neonatal morbidity at birth. The extreme prematurity (group 1) had maximum morbidity with low APGARS and high rates of sepsis.

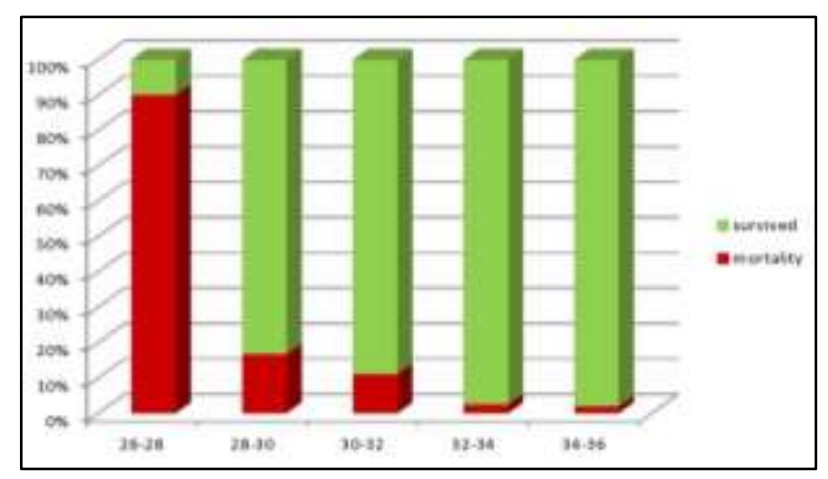

Figure 1: Neonatal mortality with respect to gestational age (in weeks).

(Figure 1), shows the mortality in each group. Nine out of ten babies died in group 1, with a mortality of $90 \%$. There was a sudden fall in the percent of mortality once the neonates crossed 28 weeks.

\section{DISCUSSION}

The recent advances in science have improved our NICU facilities. The infrastructure, the improved ventilation facilities, availability of surfactant and also the intervention of administration of antenatal corticosteroids have revolutionized preterm care. The gestational age of salvagibility of the extremely preterm infants has fallen. This has been more evident in the developed countries were the age of salvagibility is considered to be 22 weeks. But the mortality at this gestation is very high and most of them don't survive. There has been a consensus among the developed countries that neonatal resuscitation would be provided at 26 weeks, but not at 23 weeks. There is a grey area between 24-25 weeks whether resuscitation should be provided or not. ${ }^{6}$ In our present setup the gestational age of salvagibility is $26-28$ weeks. We set out to analyze these "very" preterm neonates, with the rest of the preterm before 36 weeks 6 days, their morbidities and mortalities.

Neonatal morbidities vary in different geographical regions and NICU settings. ${ }^{7}$ The antenatal risk factors, antenatal care received, administration of steroids, time interval between steroids to delivery, route of delivery, early neonatal resuscitation, and NICU care play a very important role in the incidence of neonatal morbidities and mortalities.

In our study we took low APGAR (at $5 \mathrm{~min}$ ) as <4 and $70 \%$ of the neonates in group 1 had low APGARS after which the number of neonates with low Apgar fell. Investigators have associated low Apgar scores with high mortalities even in the preterm neonates including the neonates between 24 to 28 weeks. Though controversies abound as to its reliability time and again it has been proved to be a good predictor of neonatal mortality. In group 1 the neonatal mortality was $90 \%$ on follow up. ${ }^{8-10}$

Though the percent of neonates suffering from hyperbilirubinemia was large all were the physiological type and settled with phototherapy and none required major intervention. There was no evidence of kernicterus in any of the groups. The incidence of kernicterus has been declining and is reported to be $4 \%$ in old studies. ${ }^{11}$ Current studies have reported no deaths due to kernicterus and it is said to be of a very rare occurrence. With regards to other neonatal morbidities, respiratory distress and sepsis had an overall high incidence in all the groups. Group 1 had the highest morbidity in terms of RDS $(100 \%)$ and sepsis $(70 \%)$ comparable to a study which that in the extremely preterm group $93 \%$ had RDS and $36 \%$ late onset sepsis. ${ }^{12}$

Survival remains directly proportional to gestational age and birth weight. ${ }^{12}$ The mortality rate in this group of very preterm infants in the developed countries was more than $50 \%$ as compared to $90 \%$ in our study. ${ }^{12-15}$ That is out of the 10 babies delivered in this period only one survived at the end of 6 months, begetting the question of the need of aggressive delivery and resuscitation of this group. In infants less than 25 weeks the mortality rates ranged from as low as $28 \%$ to as high as $90 \%$.It was $7 \%$ to $26 \%$ for neonates $>25$ weeks. ${ }^{16}$ The mortality rate significantly decreased from 28 weeks onwards falling from $16.7 \%$ from group 2 to as low as $1.9 \%$ at 36 weeks. Hence higher the gestational age and birth weight lower the mortality. Therefore, it becomes important to decide whether it may be adverse to decrease the viability of the gestational age when the mortality is as high as $90 \%$ and often accompanied by high morbidities, at the same time a generalized conclude on a basis that all these babies need not be resuscitated. There again, there will be the woman with bad obstetric history for whom this may be the only chance of a live baby. Therefore, in this grey area, we might have to individualize our approach to each case.

Two more issues need to be addressed. Does the route of delivery in the very preterm change the outcome? The recent reviews have shown no added benefit of the mode of delivery on the preterm neonates, though the cesarean rate for the preterm births is increasing. It might be advisable to opt to cesarean delivery in preterm births with an obstetric indication rather than for preterm itself. ${ }^{17,18}$ In group 1 in which the mortality was $90 \%, 6$ out of the ten babies $(60 \%)$ were delivered by cesarean section and the question arises as to whether we could avoid the morbidity of operative delivery in the mother were we know the mortality and morbidity of neonates in this group is high. 
In a tertiary care center, each day in NICU costs around rupees 1000 with the additional cost of ventilation, drugs and investigations. Considering our developing nation, this may be a significant financial burden on the common man with an outcome in the neonate being guarded.

The drawback of the study is that we did not follow up the babies to assess retinopathy of prematurity and long term morbidities primarily neurological outcomes. The number in the very preterm group was very low.

Most often preterm birth cannot be predicted. It strikes like a lightening on the doctors and the parents. The preparedness of both the doctor and the parent is very important in decision making in preterm regarding delivery at the edge of viability. There has been a lot of controversy among the pediatricians regarding the excessive resuscitation of the extremely preterm neonates. Ethics involved in this aggressive resuscitation also has been questioned. Obstetricians are indirectly responsible and their decision making has an important role in the management.

\section{CONCLUSIONS}

Prematurity is associated with high mortality and longterm morbidity. In the extremely preterm neonates, it is increasingly important to weigh the risks and benefits and adequately counsel the parents' who play a very important role in decision making.

Funding: No funding sources

Conflict of interest: None declared

Ethical approval: The study was approved by the Institutional Ethics Committee

\section{REFERENCES}

1. Preterm birth, 2015. Available at www.who.int/mediacentre/factsheets/fs363/en/. Accessed November 2015.

2. Blencowe H, Cousens S, Oestergaard M, Chou D, Moller AB, Narwal R, et al. National, regional and worldwide estimates of preterm birth rates in the year 2010 with time trends since 1990 for selected countries: a systemic analysis and implications. The Lancet. 2012;379(9832):2162-72.

3. Singh. U, Singh. N, Seth S. A prospective analysis of etiology and outcome of preterm labor. J Obstet Gynecol India. 2007;57(1),48-52.

4. United Nations millenium developmental goals. Available www.un.org/millenniumgoals/childhealth.shtml. Accessed 2015.

5. Born too soon - The global action report on preterm birth. 2012 Available at: www.who.int/pmnch/ media/news/2012/preterm_birth_report/en. Accessed 2 may 2012.

6. Weir M, Evans M, Coughlin K. Ethical decision making in the resuscitation of extremely premature infants: the health care professional's perspective JOGC. 2011;33(1)49-56.

7. Serenius F, Sjors G, Blennow M, Fellman V, Holmstrom G, Marsal K, et al. Express study shows significant regional differences in 1-year outcome of extremely preterm infants in Sweden; Acta Paediatrica. 2013;103:27-37.

8. Chong LH, Subeh M, Gould BJ. Low APGAR scores and neonatal mortality in extremely preterm neonates born in United States Acta Paediatr. 2010;99(12): 1785-9.

9. Forsblad K, Källén K, Marsál K, Westas LH Apgar score predicts short-term outcome in infants born at 25 gestational weeks. Acta Paediatr. 2007;96(2):166-71.

10. Iliodromiti S, Mackay DF, Smith GC, Pell JP, Nelson SM. Apgar score and the risk of causespecific infant mortality: a population-based cohort study. Lancet. 2014;384(9956):1749-55.

11. Watchko JF, Claassen D. Kernicterus in premature infants: current prevalence and relationship to NICHD Phototherapy Study exchange criteria. Pediatrics. 1994;93(6Pt1):996.

12. Stoll BJ, Hansen IN, Bell FE, Shankaran S, Laptook RA, Walsh MC, et al. Neonatal outcomes of extremely preterm infants from the NICHD Neonatal Research Network Pediatrics. 2010;126(3):443.

13. Kalimba EM, Ballot DE. Survival of extremely low birth weight infants. South African Journal of child health. 2013;7:1

14. Tyson JE, Parikh NA, Langer J, Green C, Higgins $\mathrm{RD}$. Intensive care for extreme prematurity- moving beyond gestational age. $\mathrm{N}$ Engl $\mathrm{J}$ Med. 2008;358(16):1672.

15. Field DJ, Dorling JS, Manktelow BN, Draper ES Survival of extremely premature babies in a geographically defined population: prospective cohort study of 1994-9 compared with 2000-5. BMJ. 2008;336(7655):1221.

16. Itabashi K, Horiuchi T, Kusuda S, Kabe K, Itani Y, Nakamura T, et al. Mortality rates for extremely low birth infants born in Japan in 2005. Pediatrics. 2009;123(2):445.

17. Alleman BW, Bell EF, Li L, Dagle JM, Smith PB, Ambalavanan $\mathrm{N}$, et al. Individual and center level factors affecting mortality among extremely low birth infants. Pediatrics. 2013;132(1):e175-84

18. Smrithi RCB, Remon K. Review of recent literature on the mode of delivery for singleton vertex preterm babies. Journal of pregnancy. 2011;186560.

Cite this article as: Ali J, Shivananda RP, Bhat RG, Sankar A, Kumar P, Rai L. Are aggressive deliveries of very preterm babies justified?. Int $\mathrm{J}$ Reprod Contracept Obstet Gynecol 2016;5:15458. 